\title{
O discurso da ciência e da divulgação em orientações curriculares de Língua Portuguesa*
}

\section{Marildes Marinho}

Universidade Federal de Minas Gerais, Faculdade de Educação
Para o leitor não especializado as notas aparecem como um sistema sólido, fixo e intangível; ao contrário, para o especialista elas constituem um formigueiro laborioso e agressivo. (Grafton, 1998, p. 17)

É um "protocolo de leitura" no texto acadêmico a indicação tanto quanto possível exaustiva da bibliografia sobre o tema, que deve incluir bibliografia estrangeira...

(Soares, 2001, p. 84)

\section{Estratégias enunciativas: notas de rodapé e referências bibliográficas}

Este trabalho nasceu, em 1997, de duas perguntas sobre as condições de produção de orientações curriculares para o ensino de Português no Brasil.

* Este trabalho é síntese de parte de minha tese de doutoramento, defendida no Instituto de Estudos da Linguagem da UNICAMP, sob a orientação do professor doutor Sírio Possenti. Foi apresentado no GT Alfabetização, Leitura e Escrita, durante a $25^{\mathrm{a}}$ Reunião Anual da ANPEd, realizada Caxambu, MG, de 29 setembro a 2 de outubro de 2002.
Uma delas surgiu em um seminário no Serviço de História da Educação - INRP (Institut National de Recherches Pedagogiques, França) -, quando pesquisadores desse instituto estranharam a presença de referências bibliográficas em um currículo oficial brasileiro. Alguns deles alegaram que a indicação bibliográfica, em um currículo, acarretaria dois problemas de natureza discursiva. Em primeiro lugar, as referências se tornariam uma "publicidade" oficial para as obras citadas; em segundo, a preferência por determinados autores seria, segundo eles, inconcebível num discurso governamental. Outro questionamento feito por eles diz respeito à especificidade dessas referências. Por exemplo, qual seria a função da obra de Engels (1986), A importância do trabalho na transformação do macaco em homem, para um professor de Português, texto indicado no currículo de Língua Portuguesa do Paraná (Paraná, 1990)? Entre pesquisadores brasileiros, as referências bibliográficas também têm sido objeto de polêmicas, principalmente em relação aos Parâmetros Curriculares Nacionais (PCN) (Brasil, Ministério da Educação e do Desporto, 1997, 1998), quando interrogam sobre a sofisticação dessas 
referências e sua adequação ao seu leitor preferencial. Partindo dessas especulações e do interesse em entender as estratégias enunciativas de orientações curriculares, este trabalho faz as seguintes perguntas:

Por que determinados autores são "citados" e como se constrói, nesse texto, o trabalho de citação? Como esse recurso intertextual revela uma forma particular de autoria dos currículos estaduais das últimas décadas e dos Parâmetros Curriculares Nacionais? Que efeitos podem causar, em orientações curriculares: a) a presença de uma extensa e sofisticada bibliografia? b) o uso de referências teóricas ou de citações, se considerarmos a especificidade da relação autor-leitor?

Nesse mesmo quadro das estratégias enunciativas, ${ }^{1}$ outro questionamento surgiu na leitura dos PCN1 de Língua Portuguesa, ao ver neles um número significativo de notas de rodapé. A página 88 dos $\mathrm{PCN}^{2}{ }^{2}$ é um exemplo típico do uso das notas nesse documento (ver Anexo 1). Nela, o leitor é convidado a deslocar o olhar para o rodapé, para ler cinco notas, sendo que quatro delas concentram-se no primeiro parágrafo.

É no mínimo curioso observar que notas de rodapé e referências bibliográficas não tiveram, até então, presença significativa na história dos currículos de Língua Portuguesa. Não foi objeto desta pesquisa uma abordagem histórica da retórica de docu-

${ }^{1} \mathrm{O}$ termo estratégia enunciativa, neste trabalho, toma como referência, por um lado, o conceito de leitor-modelo, tal como proposto por Eco (1986): um modo de operação textual que constitui e institui a relação autor-leitor. São escolhas sintáticas e semânticas, que estabelecem um percurso interpretativo a ser seguido pelo leitor. Ao construir as estratégias textuais (ou leitormodelo), o autor empírico também se constitui a si mesmo enquanto autor-modelo. Por outro lado, tem-se também como referência o conceito de gênero, em Bakhtin, que permite trabalhar as formas composicionais de um texto, como resultante da interação autor-leitor.

${ }^{2}$ As siglas PCN1 e PCN2, neste trabalho, se referem, respectivamente, aos Parâmetros Curriculares de Língua Portuguesa de $1^{\mathrm{a}}$ à $4^{\mathrm{a}}$ série (Brasil, Ministério da Educação e do Desporto, 1997) e de $5^{\mathrm{a}}$ à $8^{\mathrm{a}}$ série (idem, 1998) do ensino fundamental. mentos curriculares, mas basta localizar, por exemplo, um documento como os Programas de Ensino do Estado de Minas Gerais ( $5^{\mathrm{a}}$ à $8^{\mathrm{a}}$ série), de 1971, para verificar que eles não apresentam notas; apenas a disciplina de educação física indica algumas referências bibliográficas. Também nas propostas curriculares estaduais de final dos anos 1980 e 1990, é possível verificar a quase total ausência de notas de rodapé, o que reforça o seu caráter de novidade nos PCN. Dos currículos estaduais analisados, o do Distrito Federal é o único em que se pode ver uma presença significativa de notas. Ainda assim, cinco delas se prestam apenas a indicar as referências bibliográficas; outra nota explica o sentido de uma palavra: "leitmotiv: motivo condutor"; e a última ( $\left.{ }^{\circ} 7\right)$ é uma remissa aos "Fundamentos dos Planos Curriculares do $3^{\circ}$ Ciclo Básico do Programa de Língua Portuguesa - Ministério de Educação de Portugal".

Ao contrário, no discurso histórico, a nota de rodapé pode ser considerada um gênero, como sugere o historiador Grafton (1998), ao descrever a lógica e os procedimentos de um discurso erudito no processo de produção das ciências sociais.

Isto posto, parece também significativo investigar os efeitos de sentido das notas e das referências bibliográficas nos currículos contemporâneos para o ensino de Português, situando-as no contexto das questões que envolvem o lugar da universidade ou do discurso acadêmico.

\section{Os rodapés dos PCN de Língua Portuguesa ${ }^{3}$}

No documento de $1^{\mathrm{a}}$ à $4^{\mathrm{a}}$ série há 49 notas, entre as quais 25 estão distribuídas entre a página 20 e a 44 , onde se privilegia uma explicitação dos pressupostos mais gerais que devem nortear o ensino de Português. Esse primeiro grupo e a maioria das 24 notas restantes têm duas funções preferenciais: a de

\footnotetext{
${ }^{3}$ Embora esta pesquisa tenha trabalhado também com currí-
} culos de alguns estados brasileiros, o recorte preferencial privilegia aqui os $\mathrm{PCN}$. 
explicitar conceitos pressupostamente desconhecidos pelo leitor e a de argumentar ou convencer esse leitor sobre a melhor concepção teórico-metodológica para o ensino da Língua Portuguesa.

No documento de $5^{\mathrm{a}}$ à $8^{\mathrm{a}}$ série há 25 notas distribuídas entre as páginas 19 e 89 . Dezessete delas se concentram entre as páginas 19 e 40 . Assim como no documento de $1^{\mathrm{a}}$ à $4^{\mathrm{a}}$ série, a maioria dos rodapés se localiza na parte do texto que busca delinear o objeto de ensino de Português ou os pressupostos considerados desejáveis para a "área" de Língua Portuguesa.

\section{Caracterização das notas de rodapé}

A página 88 dos $\mathrm{PCN} 1$, como já dito anteriormente, é um exemplo típico. A função das suas notas 40, 41 e 43 é a de garantir maior conteúdo informacional, assim como convencer o leitor a assumir um posicionamento. Outro exemplo desse tipo de nota encontramos na página 29 desse mesmo documento. $\mathrm{O}$ fragmento destacado abaixo apresenta - apenas para exemplificação - uma composição do texto e da nota de rodapé. O trecho do texto vai até o numeral 12, onde o leitor encontra a entrada da nota, que começa pela expressão uma delas:

Tem-se observado que a afirmação de que o conhecimento é uma construção do aprendiz vem sendo interpretada de maneira espontaneísta, como se fosse possível que os alunos aprendessem os conteúdos escolares simplesmente por serem expostos a eles. Esse tipo de desinformação que parece acompanhar a emergência de práticas pedagógicas inovadoras - tem assumido formas que acabam por esvaziar a função do professor. ${ }_{12}$ [Uma delas é "agora não é mais para corrigir nada”. Isso não é verdade, a correção é bem-vinda sempre que for informativa. O problema é que, para decidir quando e qual correção é informativa, deve-se poder interpretar o erro - o que exige conhecimento nem sempre disponível]. (Brasil, 1997, p. 29)

Os elementos que introduzem os enunciados das notas (uma delas... isso não é verdade... o problema é que...) criam uma indiferenciação estrutural e se- mântica entre o miolo ${ }^{4}$ do texto e a nota. Além desse aspecto textual, as expressões grifadas sinalizam também um elemento discursivo relativo à relação autorleitor. A intromissão do autor leva para o pé da página uma interlocução tensa, já iniciada no texto, como se pode ver nas expressões maneira espontaneísta, como se fosse possível e simplesmente. Nessa passagem, pode-se visualizar a alternância de vozes que se confrontam, pois o autor opera com pressupostos referenciais considerados inovadores, tais como os das teorias construtivistas. Trata-se, segundo essas teorias, da redefinição do conceito de erro como uma formulação de hipótese, por parte da criança, no processo de aquisição da escrita. Segundo os PCN1, esse pressuposto, ao ser transposto para a sala de aula, transforma-se em espontaneísmo, por falta de conhecimento nem sempre disponível.

A quem caberia, então, esse "puxão de orelha"? Ao professor, também leitor desse documento? Às instâncias de formação e/ou de divulgação de um conhecimento não-disponível?

Já as notas 42 e 44 cumprem uma função metalingüística, por meio da substituição de uma palavra, com a finalidade de explicar os significados do termo "alínea" e de parágrafo. Essa função também se manifesta, ainda que timidamente, no uso das aspas e das citações.

\section{Aspas e citações}

As notas 22 e 44 constituem uma exceção, ao fazer uma referência explícita aos autores Todorov e Northrop Frye, numa utilização de um recurso quase completamente ausente no corpo do texto desses documentos. Embora possam ser percebidas relações intertextuais, vozes de outros autores, elas não aparecem marcadas por dispositivos convencionais, tais como aspas, citações e nomes de autores.

\footnotetext{
${ }^{4}$ Miolo se refere, segundo Compagnon (1996), ao que é emol-
} durado pela perigrafia, ou seja, pelas notas, índices, bibliografia, prefácio, prólogo, introdução, conclusão, apêndices e anexos. 
As notas de número 14, 9, 22, 23 e 38 nomeiam os autores e, em alguns casos, a obra de onde se parafrasearam os conceitos. Com exceção da nota 14 (dos PCN de $5^{\mathrm{a}}$ à $8^{\mathrm{a}}$ série) e da nota $23\left(1^{\mathrm{a}}\right.$ à $4^{\mathrm{a}}$ série), todas as outras referências não têm a indicação da obra. Cabe ao leitor, portanto, o trabalho de relacionar o nome do autor, que aparece no texto, com a lista de obras das referências bibliográficas, apresentadas no final do documento. A indicação de páginas das obras referidas não ocorre nem mesmo quando há uma citação aspeada, como no caso da nota 45 (Brasil, 1997, p. 89), que aponta Júlio Ribeiro e Napoleão Mendes de Almeida como os autores do trecho citado.

Essa é a única vez em que as aspas são utilizadas para marcar o discurso do outro, como citação. Além da função de destaque de tópicos ou subtítulos, outros usos de aspas ocorrem para a constituição de uma relação de alteridade, delimitando uma distinção do autor do documento, que pode e deve dizer o que é, didaticamante, adequado ou não. Assim, as aspas apontam o denegado, aquilo que se opõe ao "desejável" (ou desejado?), e que está presente na escola, sobretudo no que se refere aos textos ou "pseudotextos", "textos" que só servem para ensinar a ler; "textos" que não existem fora da escola (idem, p. 35); "prazer do texto" (idem, p. 37); fala “errada” (idem, p. 49), entre outras expressões aspeadas, num total de 20.

Elas servem também para afirmar "novos" conceitos:

É também no primeiro ciclo que se deve iniciar a constituição de algo que se poderia chamar de "papel de estudante”. (idem, p. 103)

O termo "escritor" está sendo utilizado aqui para... (idem, p. 65)

O termo "portador" está sendo utilizado aqui para... (idem, p. 53)

As aspas constituem um dos procedimentos formais para marcar a particular capacidade da linguagem escrita de se referir a si mesma, à própria enun- ciação. Elas apontam os campos de pertencimentos do autor e do leitor, criando um universo de cumplicidades ou de exclusão. Embora os recursos formais de citação não sejam a marca dos $\mathrm{PCN}$, o procedimento mais importante de legitimação desse discurso - a metalinguagem - tem suas formas de manifestação.

\section{Metalinguagem e autolegitimação: ciência e divulgação}

A metalinguagem é constitutiva da linguagem. Vale destacar que essa atividade é um procedimento retórico caro ao discurso científico, acadêmico. $\mathrm{O}$ conceito de atividade metalingüística compartilha aqui as referências de Geraldi (1991). O movimento entre o "novo" e o "velho" - ou as formas de estabilização e de deslocamentos de sentidos apontados por esse autor - é fundamental para a compreensão desse discurso oficial sobre o ensino de Português, particularmente no seu propósito de "novidade" e de "deslocamentos":

Na linha da história dos usos de recursos específicos, a ação sobre a linguagem é o lugar da produção de uma certa "novidade". Esta novidade poderá apagar-se no discurso em curso, no grupo, ou poderá espalhar-se de modo tal que o novo se torna o estabilizado em discursos subseqüentes. Neste sentido, a ação sobre a linguagem é produtora de novas determinações relativas da língua. [...] é responsável por deslocamentos no sistema de referências, pela construção de novas formas de representação do mundo (note-se a importância das metáforas, dos raciocínios analógicos, das comparações etc.) e pela construção de recursos gramaticalizados, atribuindo-lhes sentidos que, embora externos à gramática, são fundamentais enquanto "efeitos de sentido" no discurso. (Geraldi, 1991, p. 42-43)

Nessa nova retórica do texto curricular está em jogo a sua capacidade de trazer a "novidade". Assim procedendo, mostra-se como tal e sob a tutela de uma retórica típica do discurso acadêmico. Alguns conceitos de referência na área são explicitados nos rodapés: letramento, coesão, competência discursi- 
va, competência lingüística, competência estilística, discretização, eficácia.

Seleciono alguns desses conceitos ou itens lexicais - apresentados nos rodapés - que funcionam para o leitor como um dicionário:

${ }^{4}$ Eficácia, no uso da linguagem, refere-se aos efeitos alcançados em relação ao que se pretende. Por exemplo: convencer o interlocutor por meio de um texto argumentativo, oral ou escrito; fazer rir por meio de uma piada; etc. (Brasil, 1997, p. 22)

${ }^{5}$ Letramento, aqui, é entendido como produto da participação em práticas sociais que usam a escrita como sistema simbólico e tecnologia. São práticas discursivas que precisam da escrita para torná-las significativas, ainda que às vezes não envolvam as atividades específicas de ler ou escrever. Dessa concepção decorre o entendimento de que, nas sociedades urbanas modernas, não existe grau zero de letramento, pois nelas é impossível não participar, de alguma forma, de algumas dessas práticas. (Brasil, 1997, p. 23)

${ }^{6}$ Competência discursiva refere-se a um "sistema de contratos semânticos" responsável por uma espécie de "filtragem" que opera os conteúdos em dois domínios interligados que caracterizam o dizível: o universo intertextual e os dispositivos estilísticos acessíveis à enunciação dos diversos discursos. (Brasil, 1998, p. 23)

${ }^{7}$ Competência lingüística refere-se aos saberes que o falante/intérprete possui sobre a língua de sua comunidade e utiliza para construção das expressões que compõem os seus textos, orais e escritos, formais ou informais, independentemente de norma padrão, escolar ou culta. (Brasil, 1998, p. 23)

${ }^{8}$ Coesão, neste documento, diz respeito ao conjunto de recursos por meio dos quais as sentenças se interligam, formando um texto. (Brasil, 1997, p. 25)

${ }^{9}$ Competência estilística é a capacidade de o sujeito escolher, dentre os recursos expressivos da língua, os que mais convêm às condições de produção, à destinação, finalidades e objetivos do texto e ao gênero e suporte. (Brasil, 1998, p.23)

${ }^{15}$ Por discretização compreende-se a identificação dos diversos aspectos que estão investidos nos conhecimentos com os quais se opera nas práticas de linguagem, de modo a priorizar o tratamento de um ou de outro deles nas atividades didáticas. (PCN2, p. 36)

A estrutura lingüística básica dessas notas apresenta uma forma de sujeito/predicado ou tópico/comentário. O comentário é sempre introduzido por verbos metalingüísticos, que introduzem uma explicação/reflexão sobre os sentidos de uma expressão: "ser", "referir-se", "entender", “compreender". Vejamos, então, a estrutura sintática das notas apresentadas anteriormente:

- Eficácia, no uso da linguagem, refere-se aos efeitos...

- Letramento, aqui, é entendido como...

- Coesão, neste documento, diz respeito ao...

- Por discretização compreende-se...

- Competência estilística é a capacidade de...

São recursos que permitem ao locutor comentar a sua própria enunciação, através da explicação dos conceitos apresentados, de negociações de sentido e do monitoramento da interação autor-leitor.

Uma das formas de controle do discurso acadêmico/científico, de delimitação das suas fronteiras de sentido, é a busca de legitimidade pela inserção do outro. Esse outro pode ser marcado textualmente pelas aspas, pela citação, pela paráfrase, pelas referências bibliográficas etc. Paradoxalmente, essas marcas são pouco utilizadas nos PCN (e também nos currículos das décadas 1980/1990), exceto no que se refere às referências bibliográficas. No entanto, a ausência dessas marcas não exclui a polifonia. Os "verbetes" tratados nos rodapés ("letramento", "eficácia", "competência discursiva" etc.) não são assinalados por aspas ou créditos de autoria, mas, para um leitor "letrado", é possível situá-los num universo interdiscursivo e, às vezes, até mesmo intertextual, como veremos posteriormente.

Nos PCN, esse processo de auto-referência que posiciona a enunciação - o autor e o leitor - manifesta-se também, na superfície textual, pelos advérbios "aqui", "neste documento", ou por formas de inde- 
terminação sintática do sujeito, através da voz passiva ("compreende-se", "refere-se", "é entendido"). As marcas convencionais do discurso citado ou da presença do outro são preferencialmente alusivas, a não ser pelas referências bibliográficas e pelas sete citações nos rodapés. O apagamento do sujeito enunciador, através da voz passiva, assim como o trabalho metalingüístico de explicação seria, segundo alguns estudiosos - Moirand (1992) e Authier-Revuz (1982), por exemplo -, um recurso fundamental para o discurso de "vulgarização científica", que também se repete no discurso pedagógico. Essa "vulgarização" exigiria, para alguns autores, estratégias de aproximação de um leitor leigo, isto é, que não domina suficientemente o campo de conhecimento.

Nesse quadro de discussão dos discursos sobre ou para o ensino, parece impossível fugir à necessidade de explicitar o que se entende por "ciência", "vulgarização" e "divulgação". Zamboni (1997) se propõe a discutir os sentidos e implicações de se caracterizar determinadas práticas discursivas, particularmente no campo dos discursos da ciência, como uma vulgarização ou reformulação de um discursofonte. Fazendo um contraponto à análise de AuthierRevuz, a autora entende as atividades discursivas (de tradução, resumo, paráfrase, bem como determinadas práticas pedagógicas de adaptar um determinado conteúdo para um determinado nível de audiência) como "resultado de uma atividade discursiva que se desenvolveu em condições de produção inteiramente outras" (Zamboni, 1997, p. 86). A essas práticas discursivas ela prefere denominar de "divulgação científica”, ao invés de "vulgarização”. Aliás, a grande maioria das pesquisas francesas entende como sendo de "vulgarização" todo o discurso que pretende falar de ciência, mas não é produzido pela ciência, a exemplo das revistas de "informação" científica e dos saberes recortados pelas disciplinas escolares.

Não caberia aqui aprofundar a análise desses conceitos, por isso deixo de lado as dificuldades do conceito de "vulgarização" e atalho caminho rumo ao conceito de "divulgação científica". Essa opção não dissipa a polêmica do que seja discurso-fonte e discurso para- fraseado, original e cópia, mas diminui a força restritiva e tendenciosa do primeiro, o de "vulgarização". O que se pode observar de semelhante, nesse discurso de orientações curriculares oficiais em relação às análises dos discursos de divulgação científica, é uma aparente homogeneidade enunciativa. O efeito de tal "homogeneidade" construiria, assim, um conhecimento universal, aparentemente capaz de sintetizar e de diluir as polêmicas que emperrariam o fazer, o agir na prática cotidiana dos professores. O ponto de ancoragem das condições de produção do saber considerado legítimo, científico - e que é nos Parâmetros Curriculares instituído como o ensinável e desejável -, está sinalizado, no miolo do texto, apenas nas referências indiretas, através de um termo genérico ou dos nomes das disciplinas ou áreas de pesquisa, tais como:

- a psicologia da aprendizagem

- a psicologia cultural

- as ciências da linguagem

- psicolingüística

- sociolingüística

- pragmática

- teoria da comunicação

- semiótica

- análise do discurso

- a ciência e a literatura

- a psicogênese da língua escrita

- o avanço dessas ciências

- alguns gramáticos

- a nova crítica dos fenômenos enunciativos

- a produção científica na área

- os trabalhos... resultados de investigações

- novas propostas didáticas

- conhecimento didático acumulado

- o conhecimento disponível

- os avanços do conhecimento científico

- uma espécie de síntese do que foi possível aprender e avançar nesta década

A estrutura lingüística formada pelo artigo definido - $o$ - mais um nome ou expressão nominal $-a$ psicologia, o avanço das ciências - é uma forma de 
nomeação de uma situação, um conceito, um fenômeno, que dá a esses termos o caráter de um pressuposto ao qual o leitor não poderá opor resistência ou questionamento. Não se questiona se, de fato, aconteceu "o avanço da ciência", se há um "conhecimento disponível" e disponível para quem. Essa estratégia da nomeação é típica do discurso científico: o nomeado é o acordado, o comprovado, o descoberto, o dado. Enunciando dessa forma, com essa "simplicidade", esconde-se a complexidade dos conceitos, seu alcance e suas limitações.

Além dos conceitos particularmente nomeados nos rodapés, outros podem ser encontrados no corpo do texto, comentados ou não:

- visão muito mais funcional da língua

- reflexão sistemática sobre os aspectos discursivos do funcionamento da linguagem

- competência discursiva

- contextos efetivos de uso da linguagem

- análise tipológica de textos

- variedade lingüística

- variedade padrão

- variedade de texto

- os filhos do analfabetismo

- processo de alfabetização

- processo de aprendizagem da leitura e da escrita

- fracasso escolar

- exercícios de prontidão

- déficit

- o silabário da cartilha

Nesse caso, o discurso do outro é discretamente marcado por um conjunto de formas genéricas e universalizadoras, numa referência ao campo da ciência, da pesquisa, dos estudos em diversas áreas afins com a educação e a linguagem: história, lingüística, análise do discurso, psicolingüística, antropologia, sociolingüística, pragmática, gramática textual, literatura, semiótica, psicologia cultural, teoria da comunicação e didática, que representam as fontes de um "conhecimento acumulado", do "que foi aprendido" e está organizado nos Parâmetros :
[...] seja porque a produção científica na área tornou possível repensar sobre as questões envolvidas no ensino e na aprendizagem da língua, o fato é que a discussão da qualidade do ensino avançou bastante. Daí estes Parâmetros Curriculares Nacionais soarem como uma espécie de síntese do que foi possível aprender e avançar nesta década. (Brasil, 1997 , p. 20, grifos meus)

No processo de "produção de conhecimento" escolar, como se dá a relação com o conhecimento dito científico? Como os conceitos migram de um discurso a outro e estabelecem relações interdiscursivas, intertextuais?

As operações discursivas (o interdiscurso, o metadiscurso e a intertextualidade) instituem o quadro do que é "importante" ensinar, pautado em referências de uma comunidade letrada - as pesquisas, os pesquisadores, os artigos, as ciências, o que se sabia e o que se sabe agora, segundo os novos cânones das disciplinas contemporâneas. Uma questão fundamental, nesse momento, se refere aos componentes sócio-históricos que condicionam a escrita desse texto: as lutas travadas entre campos do conhecimento, tendências teórico-metodológicas, movimentos sociais que buscam espaço no campo das políticas oficiais (de intelectuais, educadores, editores etc.).

As notas de rodapé e as referências bibliográficas representam, nos PCN, essa relação polêmica entre o saber erudito e o da divulgação, da transposição didática, como veremos a seguir.

\section{Referências bibliográficas: por que e como determinados autores são citados?}

Ao tratar das condições de produção da escrita acadêmica e do papel do pesquisador, Magda Soares (2001), comparando essa escrita com a de textos de divulgação científica, evidencia, nas notas e nas referências, uma das características principais do "estilo" acadêmico. Ele, em geral, não dispensa notas de pé de página e agradecimentos, e quanto às citações e referências bibliográficas - retomando a epígrafe deste trabalho -, 
[...] é um "protocolo de leitura". [...] a indicação tanto quanto possível exaustiva da bibliografia sobre o tema, que deve incluir bibliografia estrangeira: uma "pequena lista" de referências bibliográficas será atestado de pouco domínio da bibliografia... e citar apenas ou sobretudo "livros publicados em português levantará a suspeita de que o autor não conhece a produção para além das fronteiras do seu país ou de sua língua. (Soares, 2001, p. 84-85)

É ainda a mesma autora que manifesta o estranhamento em relação às referências bibliográficas nos PCN de Língua Portuguesa: "o tópico sobre 'a especificidade do texto literário’ é de uma inadequação surpreendente para o pretendido leitor dos PCN (chega-se a citar - em rodapé, é verdade - Northrop Frye)" (Soares, 1997, p. 120).

Diante das críticas às sofisticadas referências, pode-se contrapor o argumento de que não é justo negar ao professor o acesso a essas leituras. Mas a simples indicação de uma lista de nomes permite esse acesso? Por que elas aparecem em um texto que nega, no seu interior, as citações, as indicações de autoria? Como o leitor desse texto pode relacionar os conceitos e pressupostos do texto aos autores, de forma a selecionar as leituras do seu interesse, que poderiam aprofundar ou responder os seus questionamentos e preencher lacunas nos seus conhecimentos? Essa relação parece ocorrer apenas para os acadêmicos que lêem esses textos, aqueles interessados na formação do professor. Sendo assim, seriam outros os critérios de indicação das referências? Quais?

Dos 80 títulos presentes nos PCN1 e 102, nos PCN2, apenas sete estão referenciados, ainda que de forma incompleta, em notas de rodapé (ver PCN1, p. 22 e 23): a primeira remete o leitor à obra A psicogênese da língua escrita, que consta das referências bibliográficas, mas sem autoria e data; a segunda, justificando a apropriação do conceito de gênero em Bronckart e Schneuwly; a terceira, para explicitar a

5 "Pequena lista" se refere à sugestão feita pela revista Ciência Hoje para as suas referências bibliográficas. relação entre literatura e realidade, com base em Northrop Frye; a quarta faz referência ao livro Portos de passagem, com o nome do autor: João Wanderley Geraldi, de onde foram retiradas as noções de "atividade lingüística", "epilingüística" e "metalingüística"; a quinta nota apresenta uma noção de parágrafo, segundo Todorov; e a última faz referência à obra de Napoleão Mendes de Almeida e Júlio Ribeiro.

Parece fácil observar que as referências explícitas a Geraldi, Bronckart e Schneuwly, e, indiretamente, a Bakhtin, Ferreiro (através da obra A psicogênese da língua escrita) e Morais e Teberosky reforçam tendências organizadoras desse discurso, como já apontado neste trabalho. No entanto, duas perguntas ficam, por enquanto, sem resposta: 1) Por que a presença de Northrop Frye e de J. R. Almeida e Napoleão Mendes de Almeida? e 2) Por que o crédito a Bronckart e Schneuwly e não a Bakhtin, quando se trata do conceito de "gênero"? Além desses créditos, outros como: "análise lingüística", "atividade epilingüística", "atividade metalingüística”, descrições das "unidades básicas de ensino de Português" e das hipóteses psicogenéticas sobre a escrita, em detrimento de outras, como "coesão", "coerência", "texto", "textualidade", "interação", "letramento", "competência", "discurso", "prontidão" etc.?

Não se poderia, aqui, ignorar processos de apagamento ou de esquecimento constitutivos do discurso, o que não é especificidade do discurso pedagógico, da vulgarização. $\mathrm{O}$ apagamento/esquecimento das origens faz com que, paulatinamente, determinados conceitos e expressões, que carregaram em determinados momentos o nome do pai, passem a um domínio do "anônimo", ou, como diz Geraldi (1991), se estabilizem. Seriam, então, os PCN (e os currículos oficiais) um dos mecanismos históricos de estabilização de conceitos no campo pedagógico? Essa estabilização significaria uma uniformização dos sentidos e uma transparência que permitem o seu reconhecimento por parte de qualquer leitor?

Para Moirand (1988) algumas expressões podem ser tacitamente ressignificadas, o que exige estratégias de controle dos seus sentidos. A autora exemplifica esse movimento com alguns conceitos, tais como 
"competência/performance", "competência de comunicação", "enunciação", "função", "intenção de comunicação", "língua/fala", "motivação", "objetivo", "paradigma/sintagma", "situação" e "estrutura", que vão perdendo aos poucos suas filiações.

Mas não estariam aí também escondidos outros elementos invisíveis das condições de produção desse discurso? Esses textos curriculares podem significar a duplicação ou mesmo a ambigüidade e complexidade do lugar do pesquisador e dos intelectuais, posicionados entre a erudição e a divulgação ou transposição didática, entre a pesquisa e as políticas públicas.

Retomando as notas como dispositivo textual e discursivo, Compagnon (1996, p. 81-82) diz que, sem as notas, o texto é inundado, já que elas são "peças de defesa (referências eruditas, acertos de contas, demarcações sutis, denegações acessórias, recuos encobertos)" que rememoram ao leitor (e ao autor) "as muletas, as estacas" - as referências - sobre as quais o texto se apóia. A nota, segundo o autor, ligaria a epígrafe à bibliografia, designando, assim, o autor como fonte de regulação, de controle da escrita. Se as referências são portas de entrada (embora situadas no final do texto), um mapa para o leitor, a sua articulação com os outros elementos periféricos e com o miolo do texto seria uma das condições para a "consistência" discursiva ou um efeito de evidência, que seduz ou convence o leitor. Admitindo essa função da perigrafia, a forma como ela se articula com o texto pode produzir efeitos inusitados.

No caso dos PCN, ao se tomar como suposto leitor o professor, pode-se pensar em uma "desarticulação" entre o texto e as referências, particularmente pela ausência de citações e remissões no interior do texto. Nesse sentido, as referências podem constituir outro texto, um apêndice, quase uma intimidação ou uma frustração. Intimidação para um leitor que não estabelece com elas uma relação mais íntima, por sugerir a hipótese de que algum problema de leitura devese ao desconhecimento dos textos que constituem o universo interdiscursivo. Frustração para o leitor (provavelmente o acadêmico) que se reconhece, num primeiro momento, naquele mapa, ao final do texto, mas que se perde nas coordenadas textuais que retomariam essa "cartografia" textual. Nessas condições, as referências funcionariam como o formigueiro laborioso para o especialista e um sistema sólido, fixo e intangível para o leitor não especializado, como sugere Grafton na epígrafe deste trabalho.

É claro que, mesmo sem as relações textualmente constituídas, a bibliografia estabelece por si só as referências de um discurso contemporâneo sobre o ensino de Português. E elas podem ser consolidadas se rastrearmos os títulos e autores nos dois volumes dos PCN e nas propostas dos estados brasileiros. $\mathrm{O}$ gráfico dos autores mais citados nesses documentos ilustra essas tendências (ver Anexo 2).

Nos PCN, entre 80 títulos do volume de $1^{\mathrm{a}}$ à $4^{\mathrm{a}}$ série e os 102 destinados à segunda fase do ensino fundamental, a reincidência de 47 títulos nos dois volumes certamente enfatiza referências de sustentação ou de legitimação do discurso oficial sobre o ensino de Português. Há títulos nacionais e estrangeiros (traduzidos ou não).

\section{De Bakhtin a Napoleão...}

Bakhtin é o primeiro da lista de autores parafraseado e literalmente "citado" nos PCN de $5^{\mathrm{a}}$ à $8^{\mathrm{a}}$ série, através da noção de gênero, apesar de não serem tributados a ele os conceitos e noções. Na obra desse autor, Estética da criação verbal, o leitor desse documento oficial poderá reencontrar os três elementos constitutivos do gênero: "conteúdo temático", "construção composicional" e "estilo", incorporados aos PCN2. Vejamos algumas passagens no documento oficial e a sua correspondência no autor russo:

Todo texto se organiza dentro de determinado gênero em função das intenções comunicativas, como parte das condições de produção dos discursos, as quais geram usos sociais que os determinam. Os gêneros são, portanto, determinados historicamente, constituindo formas relativamente estáveis de enunciados, disponíveis na cultura. São caracterizados por três elementos: a) conteúdo temático: o que é ou pode tornar-se dizível por meio do gênero; 
c) construção composicional: estrutura particular dos textos pertencentes ao gênero; c) estilo: configurações específicas das unidades de linguagem derivadas, sobretudo, da posição enunciativa do locutor; conjuntos particulares de seqüências que compõem o texto etc. (Brasil, 1998, p. 21)

Estes três elementos (conteúdo temático, estilo e construção composicional) fundem-se indissoluvelmente no todo do enunciado, e todos eles são marcados pela especificidade de uma esfera da comunicação. Qualquer enunciado considerado isoladamente é, claro, individual, mas cada esfera de utilização da língua elabora seus tipos relativamente estáveis de enunciados, sendo isso que denominamos gêneros do discurso. (Bakhtin, 1997, p. 279)

Uma dada função (científica, técnica, ideológica, oficial, cotidiana) e dadas condições, específicas para cada uma das esferas da comunicação verbal, geram um dado gênero, ou seja, um dado tipo de enunciado, relativamente estável do ponto de vista temático, composicional e estilístico. (Bakhtin, 1997, p. 284)

Esse mesmo fenômeno do anonimato ou da ausência de créditos a outros textos ocorre com um conceito de texto amplamente difundido nas vozes de teóricos da linguiística textual.

Vejamos, então, nos PCN, o conceito de texto:

O discurso, quando produzido, manifesta-se lingüisticamente por meio de textos. $\mathrm{O}$ produto da atividade discursiva oral ou escrita que forma um todo significativo, qualquer que seja sua extensão, é o texto, uma seqüência verbal constituída por um conjunto de relações que se estabelecem a partir da coesão e da coerência. Em outras palavras, um texto só é um texto quando pode ser compreendido como unidade significativa global. Caso contrário, não passa de um amontoado aleatório de enunciados. (Brasil, 1997, p. 21, grifos meus)

\section{E em Koch e Travaglia:}

Textualidade ou textura é o que faz de uma seqüencia lingüística um texto e não uma seqüência ou um amonto- ado aleatório de frases ou palavras. A seqüência é percebida como texto quando aquele que a recebe é capaz de percebêla como uma unidade significativa global. (1995, p. 26, grifos meus)

\section{Em Halliday e Hasan:}

Halliday e Hasan (1976) dizem que a coesão tem a ver com o modo como o texto está estruturado semanticamente. É, portanto, um conceito semântico que se refere às relações de significado que existem dentro do texto $e$ fazem dele um texto e não uma seqüência aleatória de frases. (apud Koch \& Travaglia, 1995, p. 26, grifos meus)

Esse trabalho de explicitação das referências conceituais dos PCN poderia continuar indefinidamente, passando pelos conceitos de coesão, coerência, letramento e outros. O que importa ver nessa estratégia de apagamento da autoria, ao mesmo tempo em que se depara com uma bibliografia extensa, é o caráter ambíguo desse gênero: é ele um gênero de divulgação, de transposição didática, ou um gênero acadêmico? Deveria ser um desses gêneros ou deveria ter outra configuração? Qual?

\section{O s currículos contemporâneos: entre a ciência e a divulgação}

Ao final desta exposição, cabe buscar uma síntese sobre a natureza desse discurso, no contexto de estratégias interdiscursivas ditas de divulgação, transmissão, vulgarização ou transposição didática de um conhecimento dito científico.

Esse discurso parece se orientar por duas estratégias enunciativas contraditórias. De um lado, busca a facilitação ou a tradução de conceitos produzidos no campo da ciência, inserindo-se, assim, no campo do discurso comumente denominado de divulgação. Por outro, se apóia em estratégias que o aproximam do discurso acadêmico. Afinal, a quem se destina esse discurso: ao professor ou aos acadêmicos?

Esse discurso parece combinar sofisticação acadêmica e facilitação do discurso de divulgação. Ao 
"facilitar", ele maximiza uma tendência do discurso didático, que utiliza determinadas noções, sem referências históricas, apresentadas como uma evidência ou como uma necessidade. Provavelmente seja essa uma das explicações para a ausência de dispositivos discursivos textuais que permitem ao leitor estabelecer as relações intertextuais, localizando historicamente os conceitos, os autores e as tendências teórico-metodológicas presentes nesses documentos. Essa estratégia seria motivada por uma necessidade de facilitar a prescrição, manifestada, entre outros discursos, nas instruções oficiais. Para Moirand (1988, p. 309-310), essa facilitação se transforma em armadilha porque cria a ilusão da generalidade, como se existisse apenas um único tipo de "terreno" no mundo e, por conseqüência, um professor "modelo", um comportamento "prototípico".

Dito de um lugar instituído, o Ministério da Educação, esse discurso alia-se à comunidade acadêmica para constituir-se em um saber incontestável, coletivo e, de certa forma, atemporal. É dessa forma que se naturalizam, se "neutralizam" ou se universalizam conceitos e pressupostos particulares, contraditórios e datados por correntes teóricas distintas ou até mesmo divergentes.

Ao se configurar por procedimentos típicos do discurso acadêmico, a exemplo das notas de rodapé e das referências bibliográficas, quais são seus efeitos? Quais são as condições de recepção por parte do seu suposto leitor preferencial, o professor? Seriam, para o leitor-professor (principalmente pela forma ambígua e "frouxa" como essas estratégias são utilizadas) um mecanismo de violência simbólica? Certamente, essas perguntas exigiriam um outro objeto e perspectiva de pesquisa, já que aqui se privilegiam as estratégias de produção e não as de recepção.

Nesse contexto amplo e genérico do ramo "científico", não se definem claramente as origens e as diversas possibilidades de sentidos dos conceitos ou noções que são "explicitadas" nos rodapés. Seria possível, então, interrogar por que esse discurso não se propõe a buscar uma maior proximidade e cumplicidade com o professor-leitor, definindo, em função dele, as suas estratégias enunciativas, de forma a privilegiar a sua vinculação com a prática concreta da sala de aula? Esse parece ser o desafio (ou impasse dos intelectuais), ${ }^{6}$ daqueles que pesquisam e escrevem na academia e nas instituições oficiais, responsáveis por políticas educacionais e orientações curriculares. Somos sujeitos de instâncias enunciativas ou de práticas sociais diferentes e, muitas vezes, divergentes. Essa condição nos impõe dificuldades e perplexidades, que merecem ser enfrentadas e analisadas, para melhor compreensão das relações entre universidade, pesquisa e ação pedagógica. Afinal, para quem pesquisamos, para quem escrevemos $?^{7} \mathrm{E}$ para quê?

MARILDES MARINHO, doutora pelo Instituto de Estudos da Linguagem da UNICAMP, é professora na Faculdade de Educação da UFMG. Publicou recentemente: O estado paradoxal da leitura ou os discursos sobre leitura no Brasil (Questio: Revista de Estudos em Educação, Sorocaba, n 2, 2001); e Professor-leitor, aluno-autor: reflexões sobre avaliação do texto escolar $\left(2^{\mathrm{a}} \mathrm{ed}\right.$., Belo Horizonte: Formato/Lê, 2001, em colaboração). Organizou: Ler e navegar: espaços e percursos da leitura (Campinas: Mercado de Letras/ALB/CEALE, 2001). Projetos atuais de pesquisa: A leitura e a produção do texto acadêmico nos cursos de graduação e pós-graduação em educação e Inovação e reforma do ensino de português no Brasil.E-mail: marildes@uai.com.br

\section{Referências bibliográficas}

AUTHIER-REVUZ, J., (1982). La mise en scène de la communication dans des discours de vulgarisation scientifique. Langue Française, $\mathrm{n}^{\circ}$ 53. Paris: Larrousse, p. 34-47.

BAKHTIN, M., (1997). Estética da criação verbal. São Paulo: Martins Fontes. Tradução de Maria Ermantina Galvão.

BRASIL, Ministério da Educação e do Desporto, (1997). Parâmetros curriculares nacionais: Língua Portuguesa $\left(1^{\mathrm{a}}\right.$ à $4^{\mathrm{a}}$ série). Brasília.

${ }^{6}$ Subtítulo do livro Para quem pesquisamos, para quem escrevemos: o impasse dos intelectuais (Garcia, 2001), tema debatido na $25^{\text {a }}$ Reunião Anual da ANPEd.

${ }^{7}$ Título do artigo de Soares (2001). 
O discurso da ciência e da divulgação em orientações curriculares de Língua Portuguesa

, (1998). Parâmetros curriculares nacionais : Língua Portuguesa ( $5^{\mathrm{a}}$ a $8^{\mathrm{a}}$ série). Brasília.

COMPAGNON, Antoine, (1996). O trabalho da citação. Belo Horizonte: Editora UFMG. Tradução de Cleonice P. B. Mourão. ECO, Umberto, (1986). O leitor modelo. In: Lector in fabula. São Paulo: Perspectiva. Tradução de Attílio Cancian.

ENGELS, F., (1986). O papel do trabalho na transformação do macaco em homem. São Paulo: Globo.

GARCIA, R.L., (org.). Para quem pesquisamos, para quem escrevemos: o impasse dos intelectuais. São Paulo: Cortez.

GERALDI, W., (1991). Portos de passagem. São Paulo: Martins Fontes.

GRAFTON, Anthony, (1998). Les origines tragiques de l'érudition: une histoire de la note en bas de page. Paris: Seuil. Tradução de Pierre Antoine Fabre.

KOCH, I., TRAVAGLIA, L.C., (1995). Texto e coerência. São Paulo: Cortez.

MAINGUENEAU, D., (1979). Les livres d'école de la republique; 1870-1914 (discours \& idéologie). Paris: Le Sycomore.

MARINHO, M., (2001). A oficialização de novas concepções para o ensino de Português no Brasil. Tese de doutorado. Instituto de Estudos da Linguagem da Universidade Estadual de Campinas (UNICAMP).
MOIRAND, Sophie, (1992). Autour de la notion de didacticité. In: Les carnets du Cediscor 1: un lieu d'inscription de la didacticité: les catastrophs naturelles dans la presse quotidienne. Paris: Presses de la Sorbonne Nouvelle. , (1988). Une histoire de discours... une analyse des discours de la revue "Le Français dans le Monde" 19611981. Paris: Hachette.

PARANÁ. Secretaria da Educação, (1990). Currículo básico para a escola do Paraná. Curitiba.

SOARES, M., (2001). Para quem pesquisamos? Para quem escrevemos? In : GARCIA, R.L. (org.). Para quem pesquisamos, para quem escrevemos : o impasse dos intelectuais. São Paulo: Cortez. , (1997). Sobre os parâmetros curriculares nacionais: algumas anotações. In : MARCUSCHI, E., SOARES, E.A.L. (org.). Avaliação educacional e currículo: inclusão e pluralidade. Recife: Editora Universitária UFPE.

ZAMBONI, Lílian Márcia Simões, (1997). Heterogeneidade e subjetividade no discurso da divulgação científica. Tese de doutorado. Instituto de Estudos da Linguagem da UNICAMP.

Recebido em outubro de 2002 Aprovado em janeiro de 2003 


\section{Anexo 1}

A história da pontuação é tributária da história das prátic as sociais de leitura. $O$ costume de ler apenas com os alhos, que caracteriz a forma modema de le $x^{40}$, incorporou ao texto um aparato gráfico cuja função é indicar ao leitor unidade para o processamento da leitura ${ }^{41}$. Na página impress a, a pontuação - ai considerados os brancos da escrita: espaços entre parágrafos e alíneas ${ }^{42}$ - organiz a o texto para a leitura visual fragmentando-o em unidades separadas de tal forma que a leitura possa teencontraý, na articulação visual da página, as conexões intelectuais ou discursivas do raciocínio. Não se trata, portanto, de indicar pausas para respirat, pois, ainda que um locutor possa usar a pontuação para isso, não é essa sua funç̧̃o no texto escrito $0^{43}$.

texto não é uma soma de frases, é um fluxo contínuo que precis a ser dividido em partes-frase que podem ou não conter partes também os apostos, por exemplo, frases que se agrupam tipograficamente em parágrafos ${ }^{44}$. A pontuação aparece sempre em posições que indicam fronteiras sintático-semânticas. Aliás, é principalmente para isso que ela se tve: para separar.

Aprender a pontuar é aprender a partir e a reagnupar o fluxo do texto de forma indicar ao leitor os sentidos propostos pelo autor obtendo assim efeitos estilísticos. $O$ escritos indica as separações (pontuando) e sua natureza (escolhendo o sinal) e com isso estabelece formas de articulação entre as partes que afetam diretamente as possibilidades de sentido.

40. A prática de leitura silenciosa disseminou-se a partir da prodhção de livros em ercala mindustrìl Até entrano o ato de ler se corfindia com o ato de recitar o text o em voz alta.

41. O estudo de textos antigos mostra que quem porturio o texto rẽo era o escritore sim o leitor Ele lin, estabeleci a sua irterpretação e preparava a litua em voz alta marando de próprio punho as pals as que corsiderava necessáris a o bom entendimento pelos ouvinter. Hoje, quando o texto inquess o é formata do para ser lido diretamente pelo olho, sem precisar pars ar pela sonorizaço do que estŕ ercrito, esta função, de estreitar o carnpo das possibilida des de interpretação indicando graficamente as uxidader de processamento e sux hierarqui interna, pertenoe ao escritor 42. Us olzse o termo "dlínea" pan derignar o recuo da lintua no início dos parágrafos. 43. Convém lembrar que se é verdh de que sempre que há uma vínguh (no écrito) há uma pausa (no oral, o contrário rẽo é verdadeiro. È cornam, por exerrplo, fazer urra palsa (no ond) ertre o sujeito e o predicado de uma onção, o que seria inconcebinel por escrit a 44. O parágrafo, segundo Todorov (DUCRO'T E TODOROV, 1988), é uma uxide de típográfica de várias fases. 


\section{Anexo 2}

Autores mais citados nos PCN e nos currículos da década de 1980-1990



